\title{
Risk Factors for Stroke among Young-Old and Old-Old Community-Dwelling Adults in Japan: The Ohasama Study
}

\author{
Keiko Murakami ${ }^{1}$, Kei Asayama ${ }^{1,2}$, Michihiro Satoh $^{3}$, Ryusuke Inoue ${ }^{4}$, Megumi Tsubota-Utsugi ${ }^{5}$, \\ Miki Hosaka ${ }^{6}$, Ayako Matsuda ${ }^{1}$, Kyoko Nomura ${ }^{1}$, Takahisa Murakami ${ }^{3,7}$, Masahiro Kikuya ${ }^{8}$, \\ Hirohito Metoki $^{3,9}$, Yutaka Imai ${ }^{2}$ and Takayoshi Ohkubo ${ }^{1}$
}

${ }^{1}$ Department of Hygiene and Public Health, Teikyo University School of Medicine, Tokyo, Japan

${ }^{2}$ Department of Planning for Drug Development and Clinical Evaluation, Tohoku University Graduate School of Pharmaceutical Sciences, Sendai, Japan

${ }^{3}$ Division of Public Health, Hygiene and Epidemiology, Faculty of Medicine, Tohoku Medical and Pharmaceutical University, Sendai, Japan

${ }^{4}$ Medical Information Technology Center, Tohoku University Hospital, Sendai, Japan

${ }^{5}$ Department of Hygiene and Preventive Medicine, Iwate Medical University School of Medicine, Iwate, Japan

${ }^{6}$ Department of Development Promotion, Clinical Research, Innovation and Education Center, Tohoku University Hospital, Sendai, Japan

${ }^{7}$ Division of Aging and Geriatric Dentistry, Department of Oral Function and Morphology, Tohoku University Graduate School of Dentistry, Sendai, Japan

${ }^{8}$ Department of Preventive Medicine and Epidemiology, Tohoku Medical Megabank Organization, Tohoku University, Sendai, Japan ${ }^{9}$ Department of Community Medical Supports, Tohoku Medical Megabank Organization, Tohoku University, Sendai, Japan

Aim: Few studies have addressed stroke risk factors in older populations, particularly among the oldold. We examined differences in traditional risk factors for stroke among the old-old compared with the young-old in community-dwelling Japanese adults.

Methods: We followed 2,065 residents aged $\geq 60$ years who had no history of stroke. Traditional risk factors for stroke were obtained from a self-administered questionnaire at baseline. We classified participants into two age categories, $60-74$ years $(n=1,502)$ and $\geq 75$ years $(n=563)$, and assessed whether traditional risk factors were differentially associated with stroke incidence according to age category. Hazard ratios were calculated by the Cox proportional hazards model, adjusting for confounding factors and competing risk of death.

Results: During a median follow-up of 12.8 and 7.9 years, 163 and 111 participants aged 60-74 and $\geq 75$ years, respectively, developed a first stroke. Hypertension was consistently associated with increased risk of stroke, regardless of age category. Diabetes mellitus was associated with increased risk of stroke in those aged 60-74 years (hazard ratio, 1.50; 95\% confidence interval, 1.00-2.25), but not in those aged $\geq 75$ years (hazard ratio, 0.65 ; 95\% confidence interval, $0.33-1.29$ ), with significant interaction by age $(P=0.035)$. No traditional risk factor other than hypertension was associated with stroke among those aged $\geq 75$ years.

Conclusion: Those with hypertension had significantly higher stroke risk among old people, while diabetes mellitus was differentially associated with stroke according to age category. Our findings indicate the importance of different prevention strategies for stroke incidence according to age category.

\section{See editorial vol. 24: 258-261}

Key words: Diabetes mellitus, Hypertension, Old-old, Stroke, Young-old

Copyright@2017 Japan Atherosclerosis Society

This article is distributed under the terms of the latest version of CC BY-NC-SA defined by the Creative Commons Attribution License.

Address for correspondence: Keiko Murakami, Department of Hygiene and Public Health, Teikyo University School of Medicine, 2-11-1 Kaga, Itabashi-ku, Tokyo 173-8605, Japan

E-mail: mkeiko-tky@umin.ac.jp

Received: March 28, 2016

Accepted for publication: June 27, 2016

\section{Introduction}

Developed countries have highly aged population structures ${ }^{1)}$. Because the incidence of stroke rises markedly with age ${ }^{2)}$, older people may receive more absolute benefits from the prevention of stroke than 
younger people. A few prospective cohort studies have shown significant associations between traditional risk factors and stroke among older people ${ }^{3-5}$, but these associations become progressively weaker with increasing age $e^{6,7)}$.

The variability between different age categories of older people should be recognized towards an accurate definition and classification of aging ${ }^{8)}$, because the older population is extremely heterogeneous ${ }^{9)}$. The rationale for this is the "young-old" and "old-old" distinction introduced by Neugarten ${ }^{10)}$ : the young-old are generally active and their functional capacity is usually conserved, while the old-old are mostly characterized by disability and dependency ${ }^{1,11)}$. Many previous studies have shown that old-old stroke patients have different risk profiles and stroke features than young-old stroke patients ${ }^{12-16)}$. These studies have been mainly hospital-based reports, and very few prospective cohort studies have assessed stroke risk among community-dwelling old-old adults, although in this population traditional risk factors for stroke seem to be less important ${ }^{7,17)}$. It is therefore unclear whether traditional risk factors for stroke in middle-aged and young-old adults are also important in the old-old.

\section{Aim}

The aim of the present study is to examine differences in traditional risk factors for stroke among the old-old compared with the young-old in community-dwelling Japanese adults. Because the competing risk of death is not negligible, particularly among the old-old, we adjusted for competing risk of death when analyzing the associations between traditional risk factors and stroke incidence.

\section{Methods}

\section{Study Population}

The present study was a part of the Ohasama Study, a longitudinal community-based observational study in Ohasama, Iwate prefecture, Japan. The geographic and demographic characteristics of the study participants have been described previously ${ }^{18,19)}$. The total population aged $\geq 60$ years was 2,614 in 1998; 2,348 provided written informed consent to participate (response rate $89.8 \%$ ). The participants or their relatives completed the self-administered questionnaire between February 1 and March 28, 1998. A total of 283 participants were excluded for the following reasons: a history of stroke before the baseline survey $(n=236)$, unwillingness to take part in follow-up $(n=46)$, or relatives responding after the death of the participant $(n=1)$. Data from the remaining 2,065 participants were analyzed. The institutional review board of Tohoku University School of Medicine and of Pharmaceutical Sciences and the Department of Health of the Ohasama Town Government approved this study.

\section{Traditional Risk Factors}

Traditional risk factors for stroke were obtained from the baseline self-administered questionnaire. Self-reported body weight and height were used to calculate body mass index, which was classified as $<18.5$, $18.5-24.9$, or $\geq 25 \mathrm{~kg} / \mathrm{m}^{2}$. Among the participants, 935 attended health checkups provided by the town in November 1997, and we compared the selfreported values at the baseline survey with the measured values at the health checkup; Pearson's correlation was 0.81 for body mass index. Hypertension was defined as a diagnosed history of hypertension or current use of antihypertensive drugs. Diabetes mellitus, hypercholesterolemia, heart disease, and kidney disease were defined as having been diagnosed with the disease, including being currently under treatment. Smoking status was categorized in three groups: current, former, and never. Alcohol intake was dichotomized as current and former/never because of the small number of respondents who answered 'former.' Marital status was dichotomized into married and single/divorced/widowed. Educational attainment was dichotomized into junior high school and senior high school or higher. Habitual exercise was determined by answers to the question, "How many times do you normally exercise per week?" Responses were classified as rarely/never, 1-2 hours/week, or $\geq 3$ hours/week. Parental histories of hypertension and stroke were defined as positive if participants reported that one parent had a history of disease.

\section{Follow-Up and Outcomes}

Follow-up of each participant was continued until the occurrence of one of the following censoring events: stroke incidence, death, loss to follow-up because of moving away from Ohasama town, or the end of our follow-up period (November 30, 2010). Residence in Ohasama was confirmed by the residents' registration cards, which are used for pensions and social security benefits in Japan. Stroke incidence was determined by reviewing the Stroke Registration System of Iwate Prefecture, death certificates, National Health Insurance receipts, Later Elder's Insurance receipts, and questionnaires sent to each household at the time of health checkups. This information was then confirmed by checking the medical charts of Ohasama Hospital, which is the only hospital in the town and where $\geq 90 \%$ of participants had regular 
checkups. Among all stroke cases registered until $2010,97.7 \%$ were confirmed by computed tomography or magnetic resonance imaging of the brain. The diagnostic criteria of stroke and its subtypes were based on the system for the Classification of Cerebrovascular Disease III by the National Institute of Neurological Disorders and Stroke ${ }^{20)}$. Fatal cases of stroke were defined as death from stroke within 28 days of stroke incidence ${ }^{21)}$. The present analysis considered only the first stroke incidence. Deaths from stroke ascertained only by death certificates were not included in stroke cases, as these diagnoses and dates of incidence were uncertain. Transient ischemic attacks were not included as stroke.

\section{Statistical Analysis}

Baseline characteristics of participants aged 60-74 years and $\geq 75$ years were compared using the chi-square test. The Cox proportional hazards model was used to explore the associations between traditional risk factors and first stroke incidence. To weigh competing risk of death (death from causes other than stroke, such as cancer and heart disease) among the older population, the Cox model fitted a proportional subdistribution hazards regression model with weights for those who underwent competing risk of death ${ }^{22,23)}$. Person-years in the follow-up period were counted from the date of the baseline survey to the occurrence of one of the censoring events, whichever came first. For those who were lost to follow-up, the last confirmed date of their presence in Ohasama was used as the date of censoring.

A two-step process was used to determine the best model for the study. First, we used the age- and sex-adjusted Cox model to determine the separate associations of all variables with stroke incidence. Variables that fulfilled a significance of $P<0.20$ in these models were then simultaneously entered into a multivariate-adjusted model including age and $\operatorname{sex}^{24)}$. This multivariate-adjusted analysis was performed separately by age category. We further examined whether age category modified the associations between risk factors and stroke by cross-product interaction terms. We conducted sensitivity analyses stratified by sex. Identical analyses were conducted according to the stroke subtypes of cerebral infarction and hemorrhagic stroke (intracerebral hemorrhage and subarachnoid hemorrhage combined). For missing values at baseline, the single imputation method with regression on age and sex was conducted in multivariate analyses. Because similar results were obtained before and after imputation, we present only the results with imputation.

All analyses were conducted using STATA 12.0
(StataCorp LP, College Station, TX, USA). A twotailed $P<0.05$ was considered statistically significant.

\section{Results}

The baseline characteristics of participants are shown in Table 1. Significant differences in the prevalence of traditional risk factors for stroke were observed between those aged 60-74 years and those aged $\geq 75$ years, except for diabetes mellitus and hypercholesterolemia.

The median duration of follow-up was 12.8 years among those aged 60-74 years and 7.9 years among those aged $\geq 75$ years. During 16,472 person-years among those aged 60-74 years, 324 deaths and 163 incident cases of first stroke (19 fatal cases; 11.7\%) were observed: 113 cerebral infarctions, 33 intracerebral hemorrhages, 15 subarachnoid hemorrhages, 1 other type, and 1 unspecified case. During 4,367 person-years among those aged $\geq 75$ years, 371 deaths and 111 incident cases of first stroke (13 fatal cases; $11.7 \%$ ) were observed: 89 cerebral infarctions, 21 intracerebral hemorrhages, and 1 unspecified case. Of those stroke cases ascertained only by death certificates, 3 cases were among those aged 60-74 years and 16 cases were among those aged $\geq 75$ years.

Age- and sex-adjusted hazard ratios (HRs) and 95\% confidence intervals (CIs) for stroke incidence according to traditional risk factors among the total population (those aged $\geq 60$ years) are presented in Table 2. Older age, male sex, hypertension, diabetes mellitus, heart disease, current alcohol drinking, and lower educational attainment reached significance $(P$ $<0.20)$ and were used in the following analyses.

Older age, hypertension, diabetes mellitus, and lower educational attainment were significantly associated with stroke incidence among those aged 60-74 years after multivariate adjustment, while only hypertension was a significant risk factor for stroke among those aged $\geq 75$ years (Fig. 1). The interaction of diabetes mellitus with age categories was statistically significant $(P=0.035)$. No significant interaction was found between age categories and any other variables. Hypertension was associated with a higher probability of stroke incidence among both those aged 60-74 years (HR, 2.12; 95\% CI, 1.51-2.98) and those aged $\geq 75$ years (HR, 1.59; 95\% CI, 1.07-2.36). However, diabetes mellitus was associated with increased stroke risk only among those aged 60-74 years (HR, 1.50; $95 \%$ CI, 1.00-2.25), not among those aged $\geq 75$ years (HR, 0.65; 95\% CI, 0.33-1.29). We also conducted standard Cox regression analyses, and obtained similar results (Supplemental Table 1). Although the interaction by sex on the association of educational attain- 
Table 1. Baseline characteristics in the Ohasama Study, Japan, 1998

\begin{tabular}{|c|c|c|c|c|}
\hline Variables, $n(\%)$ & $\begin{array}{c}\text { Total } \\
n=2065\end{array}$ & \multicolumn{2}{|c|}{ Age category } & $P$ value \\
\hline Men & $840(40.7)$ & $648(43.1)$ & $192(34.1)$ & $<0.001$ \\
\hline Body mass index & & & & $<0.001$ \\
\hline$<18.5 \mathrm{~kg} / \mathrm{m}^{2}$ & $98(5.6)$ & $55(4.1)$ & $43(10.8)$ & \\
\hline Hypertension & $965(46.7)$ & $656(43.7)$ & $309(54.9)$ & $<0.001$ \\
\hline Diabetes mellitus & $262(12.7)$ & $198(13.2)$ & $64(11.4)$ & 0.27 \\
\hline Hypercholesterolemia & $266(12.9)$ & $205(13.7)$ & $61(10.8)$ & 0.089 \\
\hline Heart disease & $219(10.6)$ & $133(8.9)$ & $86(15.3)$ & $<0.001$ \\
\hline Kidney disease & $66(3.2)$ & $38(2.5)$ & $28(5.0)$ & 0.005 \\
\hline Current drinker & $648(31.4)$ & $519(34.6)$ & $129(22.9)$ & $<0.001$ \\
\hline Married & $1283(70.7)$ & $1058(79.7)$ & $225(46.1)$ & $<0.001$ \\
\hline Educational attainment, junior high school & $1579(84.8)$ & $1148(83.1)$ & $431(89.8)$ & $<0.001$ \\
\hline Habitual exercise & & & & 0.030 \\
\hline$\geq 3$ hours/week & $172(9.6)$ & $129(9.7)$ & $43(9.4)$ & \\
\hline 1-2 hours/week & $286(16.0)$ & $230(17.3)$ & $56(12.2)$ & \\
\hline Rarely/Never & $1329(74.4)$ & $969(73.0)$ & $360(78.4)$ & \\
\hline Parental history of hypertension & $377(18.3)$ & $303(20.2)$ & $74(13.1)$ & $<0.001$ \\
\hline Parental history of stroke & $566(27.4)$ & $436(29.0)$ & $130(23.1)$ & 0.007 \\
\hline
\end{tabular}

Values are the number of participants (\%). Values for body mass index, marital status, educational attainment, and habitual exercise were available for $1743,1816,1862$, and 1787 participants, respectively. $P$ denotes the significance of the difference between age categories using the chi-square test.

Table 2. Age- and sex-adjusted hazard ratios for stroke incidence

\begin{tabular}{lcc}
\hline Variables & Age- and sex- adjusted & P value \\
\hline Age (per 1 standard deviation) & HR $(95 \%$ CI) & \\
Men (vs. women) & $1.47(1.32-1.63)$ & $<0.001$ \\
BMI, $<18.5 \mathrm{~kg} / \mathrm{m}^{2}$ (vs. 18.5-24.9) & $1.27(1.00-1.62)$ & 0.050 \\
BMI, $\geq 25.0 \mathrm{~kg} / \mathrm{m}^{2}$ (vs. 18.5-24.9) & $1.10(0.64-1.88)$ & 0.74 \\
Hypertension & $0.92(0.67-1.26)$ & 0.61 \\
Diabetes mellitus & $1.98(1.54-2.55)$ & $<0.001$ \\
Hypercholesterolemia & $1.29(0.92-1.79)$ & 0.14 \\
Heart disease & $0.92(0.63-1.36)$ & 0.69 \\
Kidney disease & $1.26(0.89-1.79)$ & 0.19 \\
Current smoker (vs. never) & $0.71(0.34-1.50)$ & 0.37 \\
Former smoker (vs. never) & $1.25(0.87-1.80)$ & 0.22 \\
Current drinker & $0.85(0.53-1.34)$ & 0.47 \\
Single/divorced/widowed (vs. married) & $1.29(0.97-1.72)$ & 0.077 \\
Junior high school (vs. senior high school or higher) & $0.91(0.65-1.27)$ & 0.58 \\
Habitual exercise, $\geq 3$ hours/week (vs. rarely/never) & $1.67(1.08-2.59)$ & 0.022 \\
Habitual exercise, 1-2 hours/week (vs. rarely/never) & $0.81(0.50-1.30)$ & 0.38 \\
Parental history of hypertension & $0.99(0.69-1.42)$ & 0.97 \\
Parental history of stroke & $0.97(0.70-1.33)$ & 0.83 \\
\hline
\end{tabular}

Each hazard ratio (HR) and 95\% confidence interval (CI) was adjusted by age and sex, while age was adjusted by sex and vice versa. Age per 1 standard deviation corresponded to 7.6 years. 


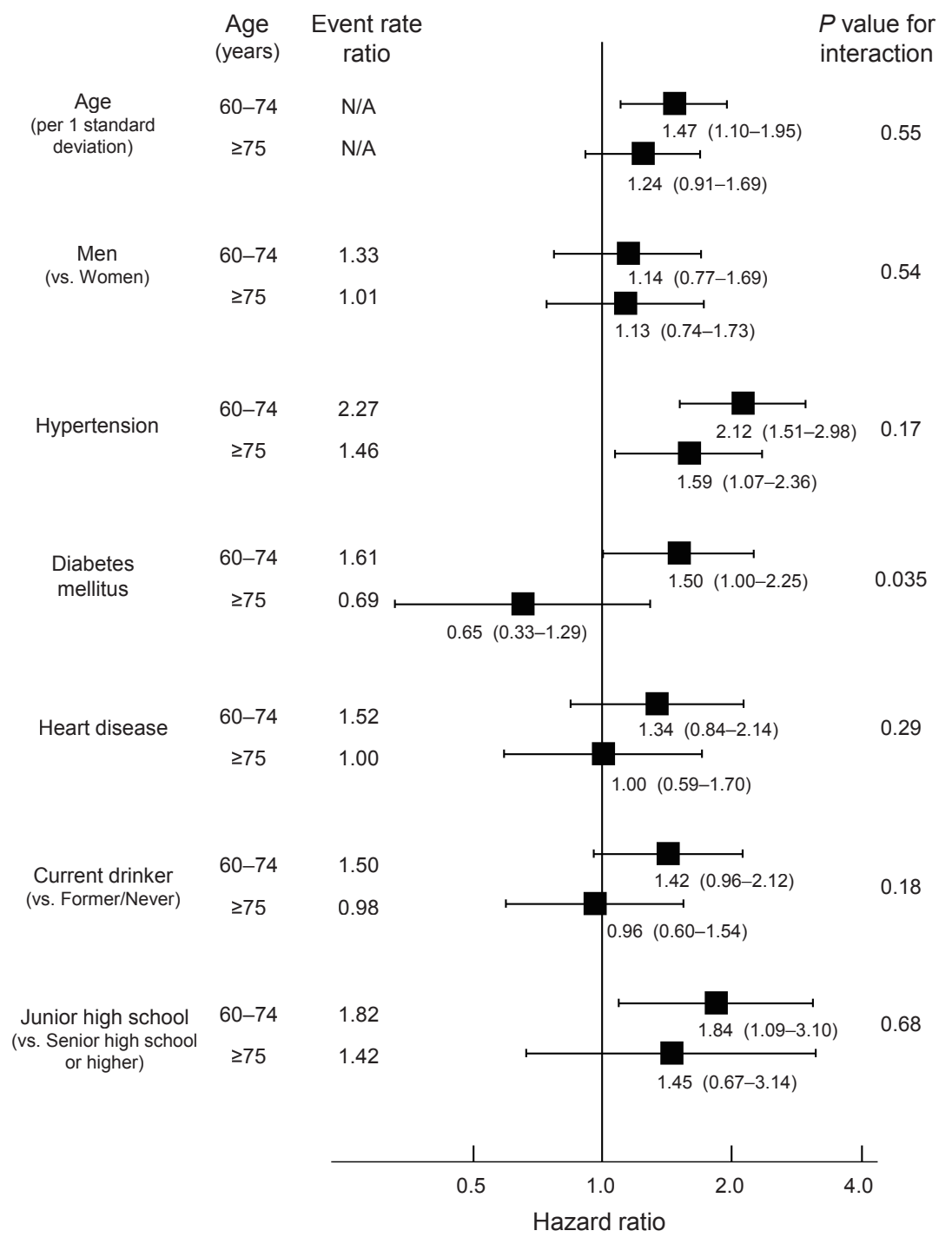

Fig. 1. Event rate and hazard ratios for stroke incidence among participants aged $60-74$ years $(n=1,520)$ and $\geq 75$ years $(n=563)$

Event rate ratios were calculated based on crude event rate in each subgroup, while hazard ratios were adjusted for all other variables. Filled squares represent point estimates and horizontal lines denote the $95 \%$ confidence interval. Age per 1 standard deviation corresponded to 7.6 years. $P$ denotes the significance of interaction between age categories $(60-74$ years and $\geq 75$ years) and each variable.

ment with stroke was statistically significant among those aged $60-74$ years $(P=0.012)$, there was little difference between men and women on the other variables (Supplemental Table 2).

Results were confirmatory when cerebral infarction was assessed instead of total stroke, although statistical significance was reduced because of smaller event numbers. Diabetes mellitus was associated with a higher risk of cerebral infarction only among those aged 60-74 years, but not among those aged $\geq 75$ years (Supplemental Table 3). To predict hemor- rhagic stroke, current alcohol drinking was the only significant risk factor among those aged 60-74 years (Supplemental Table 4).

\section{Discussion}

The present cohort study demonstrated that hypertension was consistently associated with increased risk of stroke regardless of age category, and that diabetes mellitus was not associated with excess risk of stroke among those aged $\geq 75$ years. No tradi- 
tional risk factor other than hypertension was associated with first stroke among those aged $\geq 75$ years.

Traditional risk factors had weaker associations with stroke among those aged $\geq 75$ years than among those aged 60-74 years. This finding supports the argument that the associations between traditional risk factors and stroke are attenuated with advancing age ${ }^{6,7)}$. There are two possible explanations for this finding ${ }^{6}$. First, survivors with risk factors in the old-old age group may differ through selection. Those who are susceptible to risk factors are more likely to have had events earlier in life, and survival to old age with risk factors may be an indicator that they are less susceptible to such risk factors ${ }^{6}$. . Second, the impact of some risk factors may be modified because of physiologic changes that occur during the aging process. Such changes can be amplified in old-old adults, who are mostly characterized by vulnerability ${ }^{111}$. These cannot be separated, and both would contribute to the attenuated associations with advancing age. Some traditional risk factors such as smoking and obesity had no association with stroke incidence irrespective of age category in this population of those aged $\geq 60$ years, which suggests that the attenuated associations of traditional risk factors with stroke would have begun already at young-old age.

Hypertension and diabetes mellitus are wellknown risk factors for stroke incidence ${ }^{25)}$. In the present study, hypertension had consistently significant associations with stroke, while diabetes mellitus had no association with stroke among those aged $\geq 75$ years. The lower prevalence of diabetes mellitus than that of hypertension suggests that a larger sample is needed to detect a true association between diabetes mellitus and stroke than is needed to detect an association between hypertension and stroke. Nevertheless, in our study, the association between diabetes mellitus and stroke was positive among those aged $60-74$ years and negative among those aged $\geq 75$ years, with significant interaction for these age categories (Fig. 1; $P=0.035)$.

A prospective cohort study showed that only higher blood pressure was associated with stroke among community-dwelling adults aged 85 years ${ }^{17)}$. Pooling individual data from 10 Japanese cohorts demonstrated the positive associations between blood pressure and death from cardiovascular disease even among the old-old, with a greater strength observed in younger age groups ${ }^{26}$. Recent intervention trials supported that treatment of hypertension contributed to stroke prevention in older patients ${ }^{27)}$. Taken together, hypertension appears to be a major risk factor for stroke even among the old-old, although the contribution of hypertension to stroke becomes progressively weaker with increasing age $\mathrm{e}^{6,7,13,28)}$

Inconsistent findings were reported on the associations between diabetes mellitus and stroke among older adults $4,6,7)$. Hospital-based stroke registries showed that old-old stroke patients had significantly lower prevalence of diabetes mellitus than other age groups $^{12-16,29,30)}$. Diabetes mellitus is strongly associated with other cardiovascular risk factors, such as hypertension and dyslipidemia ${ }^{31,32)}$. The weaker contribution of diabetes mellitus with advancing age can be explained by its coexistence with other cardiovascular risk factors, which results in fatal cardiovascular events at a younger age ${ }^{15,31)}$. The aforementioned survival bias ${ }^{6}$ may be more marked in diabetes mellitus than in other risk factors, although this remains to be proved. Previous studies have shown that functional capacity or psychosocial status, such as social role ${ }^{19)}$, cognitive impairment ${ }^{33)}$, and depression ${ }^{34)}$, are significantly associated with stroke incidence even after adjusting for traditional risk factors among old-old adults. For those aged $\geq 75$ years, these factors are likely to have stronger associations with stroke incidence than traditional risk factors.

Significant interaction by sex was observed only for educational attainment; those whose educational attainment was junior high school had significantly higher risk of stroke than those whose educational attainment was senior high school or higher, but this association was found only for women. This result is consistent with a recent review indicating that low socioeconomic status is associated with an increased risk of stroke, and that the association might be stronger in women than in men ${ }^{35}$. However, this association is partially inconsistent among Japanese women; for example, one study found a U-shaped association (women whose educational attainment was high school had the lowest risk of stroke ${ }^{36)}$ ). We could not determine whether there was a U-shaped association in the present study, because the proportion of women whose educational attainment was college or higher was very low $(3.7 \%)$. Further studies are needed to clarify the association between educational attainment and stroke in Japan, because assessing socioeconomic status in women (particularly partnered women) is challenging ${ }^{37)}$ and cultural differences might be expected to influence socioeconomic inequalities in women's health ${ }^{38)}$.

The present study must be interpreted within the context of its potential limitations. First, information on all risk factors was self-reported and misclassification is possible. In prospective studies, misclassification is typically considered nondifferential and therefore is expected to lead to an underestimation of risk. If the validity of self-reported histories reduces with 
increasing age, this could partly explain the weaker associations of traditional risk factors with stroke among those aged $\geq 75$ years than among those aged 60-74 years. However, the prevalence of undetected hypertension and diabetes mellitus may be relatively small because of nationwide health screenings in Japan $^{39)}$. Second, our study population consisted of residents from a Japanese rural district, and our current findings might not be generalizable to Western populations, in whom not stroke but myocardial infarction is the dominant cardiovascular complication. Nevertheless, the representativeness of the sampled area will be high because of the high response rate $(89.8 \%)$. Third, the validity of parental histories of hypertension and stroke remains questionable. Recall of parental hypertension may be difficult to confirm because of the less frequent opportunity for measuring blood pressure or different hypertension criteria when the participants' parents were alive and because of recall bias ${ }^{40)}$. Self-reported parental history of stroke is sometimes inaccurate; in the Framingham Offspring Study, a positive offspring report of parental early-onset stroke had relatively low predictive value, whereas a negative offspring report had high predictive value ${ }^{41)}$. Other factors that are easier to remember (e.g., parental longevity) may be more accurate predictors for stroke than offspring reports of parental history of hypertension and stroke ${ }^{42)}$. Finally, we cannot estimate entire confounding factors (e.g., mental disorders or physical activities) that may be associated with stroke risk. Despite these limitations, we could examine the associations between traditional risk factors and stroke incidence among old-old adults, about which there is little evidence. Identification and quantitative assessment of particular risk factors for stroke among the old-old in the present study has important preventive implications. In addition, a better knowledge of age differences in stroke risk profiles may be useful for intervention points for risk modification.

\section{Conclusion}

The present study showed that the sets of traditional risk factors for stroke among those aged 60-74 and $\geq 75$ years differed: all older people with hypertension had consistently high stroke risk, while the association between diabetes mellitus and stroke was weakened in those aged $\geq 75$ years at baseline. No traditional risk factors other than hypertension were associated with stroke among those aged $\geq 75$ years. If survival bias (i.e., those who are susceptible to risk factors have a higher probability of stroke incidence earlier in life) attenuates the associations between traditional risk factors and stroke with increasing age, ear- lier treatment of risk factors such as diabetes mellitus before $\geq 75$ years would be useful in preventing stroke incidence. Our findings support the importance of different prevention strategies for stroke incidence according to age category.

\section{Acknowledgements}

We are grateful to the residents in Ohasama, and to staff members of the Hanamaki City Government, Ohasama Hospital, and Iwate Prefecture Stroke Registry for their valuable support on the Ohasama study project.

This study was supported by Grants for Scientific Research (23249036, 23390171, 24390084, 24591060, 24790654, 25253059, 25461083, 25461205, 25860156, 26282200, and 26860093) from the Ministry of Education, Culture, Sports, Science, and Technology, Japan; a Grant-in-Aid from the Japan Society for the Promotion of Science (JSPS) fellows $\left(25^{*} 7756,25^{*} 9328,26^{*} 857\right.$ and $\left.27^{*} 656\right)$; the Japan Arteriosclerosis Prevention Fund; Intramural Research Fund (22-4-5) for Cardiovascular Diseases of National Cerebral and Cardiovascular Center; and a Health Labour Sciences Research Grant (H26-Junkankitou [Seisaku]-Ippan-001) from the Ministry of Health, Labour, and Welfare; and A Scheme to Revitalize Agriculture and Fisheries in Disaster Area through Deploying Highly Advanced Technology (NouEi 2-02) from the Ministry of Agriculture, Forestry and Fisheries, Japan.

\section{Conflicts of Interest}

There are no conflicts of interest related to the present study.

\section{References}

1) Christensen K, Doblhammer G, Rau R, Vaupel JW: Ageing populations: the challenges ahead. Lancet, 2009; 374: 1196-1208

2) Seshadri S, Beiser A, Kelly-Hayes M, Kase CS, Au R, Kannel WB, Wolf PA: The lifetime risk of stroke: estimates from the Framingham Study. Stroke, 2006; 37: 345-350

3) Kaarisalo MM, Immonen-Räihä P, Marttila RJ, Lehtonen A, Torppa J, Tuomilehto J: Long-term predictors of stroke in a cohort of people aged 70 years. Arch Gerontol Geriatr, 2000; 31: 43-53

4) Rodgers H, Greenaway J, Davies T, Wood R, Steen N, Thomson R: Risk factors for first-ever stroke in older people in the north East of England: a population-based study. Stroke, 2004; 35: 7-11

5) Simons LA, McCallum J, Friedlander Y, Simons J: Risk factors for ischemic stroke: Dubbo Study of the elderly. 
Stroke, 1998; 29: 1341-1346

6) Odden MC, Shlipak MG, Whitson HE, Katz R, Kearney PM, Defilippi C, Shastri S, Sarnak MJ, Siscovick DS, Cushman M, Psaty BM, Newman AB: Risk factors for cardiovascular disease across the spectrum of older age: the Cardiovascular Health Study. Atherosclerosis, 2014; 237: 336-342

7) Singh GM, Danaei G, Farzadfar F, Stevens GA, Woodward M, Wormser D, Kaptoge S, Whitlock G, Qiao Q, Lewington S, Di Angelantonio E, Vander Hoorn S, Lawes CM, Ali MK, Mozaffarian D, Ezzati M; Global Burden of Metabolic Risk Factors of Chronic Diseases Collaborating Group; Asia-Pacific Cohort Studies Collaboration (APCSC); Diabetes Epidemiology: Collaborative analysis of Diagnostic criteria in Europe (DECODE); Emerging Risk Factor Collaboration (ERFC); Prospective Studies Collaboration (PSC): The age-specific quantitative effects of metabolic risk factors on cardiovascular diseases and diabetes: a pooled analysis. PLoS One, 2013; 8: e65174

8) Jacobs JM, Maaravi Y, Cohen A, Bursztyn M, Ein-Mor E, Stessman J: Changing profile of health and function from age 70 to 85 years. Gerontology, 2012; 58: 313-321

9) Lowsky DJ, Olshansky SJ, Bhattacharya J, Goldman DP: Heterogeneity in healthy aging. J Gerontol A Biol Sci Med Sci, 2014; 69: 640-649

10) Neugarten BL: Age groups in American society and the rise of the young-old. Ann Am Acad Pol Soc Sci, 1974; 415: 187-198

11) Baltes PB, Smith J: New frontiers in the future of aging: from successful aging of the young old to the dilemmas of the fourth age. Gerontology, 2003; 49: 123-135

12) Arboix A, Miguel M, Císcar E, García-Eroles L, Massons J, Balcells M: Cardiovascular risk factors in patients aged 85 or older with ischemic stroke. Clin Neurol Neurosurg, 2006; 108: 638-643

13) Auriel E, Gur AY, Uralev O, Brill S, Shopin L, Karni A, Tsarfaty SS, Bornstein NM: Characteristics of first ever ischemic stroke in the very elderly: profile of vascular risk factors and clinical outcome. Clin Neurol Neurosurg, 2011; 113: 654-657

14) Gur AY, Tanne D, Bornstein NM, Milo R, Auriel E, Shopin L, Koton S; NASIS Investigators: Stroke in the very elderly: characteristics and outcome in patients aged $\geq 85$ years with a first-ever ischemic stroke. Neuroepidemiology, 2012; 39: 57-62

15) Kotsaftis P, Ntaios G, Savopoulos C, Kiparoglou R, Agapakis D, Baltatzi M, Tsesmeli N, Hatzitolios A: Trend in incidence of cardiovascular risk factors in elderly and over-aged stroke patients between 2003 and 2007 in Greece. Arch Gerontol Geriatr, 2010; 50: e31-e35

16) Lee M, Huang WY, Weng HH, Lee JD, Lee TH: Firstever ischemic stroke in very old Asians: clinical features, stroke subtypes, risk factors and outcome. Eur Neurol, 2007; 58: 44-48

17) Liebetrau M, Steen B, Skoog I: Stroke in 85-year-olds: prevalence, incidence, risk factors, and relation to mortality and dementia. Stroke, 2003; 34: 2617-2622

18) Ohkubo T, Asayama K, Imai Y: The value of self-measured home blood pressure in predicting stroke. Expert Rev Neurother, 2006; 6: 163-173

19) Murakami K, Tsubota-Utsugi M, Satoh M, Asayama K,
Inoue R, Ishiguro A, Matsuda A, Kanno A, Yasui D, Murakami T, Metoki H, Kikuya M, Imai Y, Ohkubo T: Impaired higher-level functional capacity as a predictor of stroke in community-dwelling older adults: the Ohasama study. Stroke, 2016; 47: 323-328

20) National Institute of Neurological Disorders and Stroke: Special report from the National Institute of Neurological Disorders and Stroke. Classification of cerebrovascular diseases III. Stroke, 1990; 21: 637-676

21) World Health Organization MONICA Project: Event registration data component, MONICA manual version 1.1. Document for meeting of MONICA principal investigators, 1986

22) Fine JP, Gray RJ: A proportional hazards model for the subdistribution of a competing risk. J Am Stat Assoc, 1999; 94: 496-509

23) Driver JA, Djoussé L, Logroscino G, Gaziano JM, Kurth $\mathrm{T}$ : Incidence of cardiovascular disease and cancer in advanced age: prospective cohort study. BMJ, 2008; 337: a2467

24) Muraga K, Nishiyama Y, Otsuka T, Ueda M, Abe A, Katayama Y: The asymmetric dimethylarginine level is associated with the predicted stroke risk in Japanese women. J Atheroscler Thromb, 2014; 21: 640-647

25) Meschia JF, Bushnell C, Boden-Albala B, Braun LT, Bravata DM, Chaturvedi S, Creager MA, Eckel RH, Elkind MS, Fornage M, Goldstein LB, Greenberg SM, Horvath SE, Iadecola C, Jauch EC, Moore WS, Wilson JA; American Heart Association Stroke Council; Council on Cardiovascular and Stroke Nursing; Council on Clinical Cardiology; Council on Functional Genomics and Translational Biology; Council on Hypertension: Guidelines for the primary prevention of stroke: a statement for healthcare professionals from the American Heart Association/ American Stroke Association. Stroke, 2014; 45: 37543832

26) Fujiyoshi A, Ohkubo T, Miura K, Murakami Y, Nagasawa SY, Okamura T, Ueshima H; Observational Cohorts in Japan (EPOCH-JAPAN) Research Group: Blood pressure categories and long-term risk of cardiovascular disease according to age group in Japanese men and women. Hypertens Res, 2012; 35: 947-953

27) Beckett NS, Peters R, Fletcher AE, Staessen JA, Liu L, Dumitrascu D, Stoyanovsky V, Antikainen RL, Nikitin Y, Anderson C, Belhani A, Forette F, Rajkumar C, Thijs L, Banya W, Bulpitt CJ; HYVET Study Group: Treatment of hypertension in patients 80 years of age or older. $\mathrm{N}$ Engl J Med, 2008; 358: 1887-1898

28) Wolf PA, Abbott RD, Kannel WB: Atrial fibrillation as an independent risk factor for stroke: the Framingham Study. Stroke, 1991; 22: 983-988

29) Olindo S, Cabre P, Deschamps R, Chatot-Henry C, René-Corail P, Fournerie P, Saint-Vil M, May F, Smadja D: Acute stroke in the very elderly: epidemiological features, stroke subtypes, management, and outcome in Martinique, French West Indies. Stroke, 2003; 34: 15931597

30) Rojas JI, Zurrú MC, Romano M, Patrucco L, Cristiano E: Acute ischemic stroke and transient ischemic attack in the very old-risk factor profile and stroke subtype between patients older than 80 years and patients aged less than 80 
years. Eur J Neurol, 2007; 14: 895-899

31) Hatzitolios AI, Didangelos TP, Zantidis AT, Tziomalos K, Giannakoulas GA, Karamitsos DT: Diabetes mellitus and cerebrovascular disease: which are the actual data? J Diabetes Complications, 2009; 23: 283-296

32) Tuttolomondo A, Pinto A, Salemi G, Di Raimondo D, Di Sciacca R, Fernandez P, Ragonese P, Savettieri G, Licata G: Diabetic and non-diabetic subjects with ischemic stroke: differences, subtype distribution and outcome. Nutr Metab Cardiovasc Dis, 2008; 18: 152-157

33) Sabayan B, Gussekloo J, de Ruijter W, Westendorp RG, de Craen AJ: Framingham stroke risk score and cognitive impairment for predicting first-time stroke in the oldest old. Stroke, 2013; 44: 1866-1871

34) Liebetrau M, Steen B, Skoog I: Depression as a risk factor for the incidence of first-ever stroke in 85-year-olds. Stroke, 2008; 39: 1960-1965

35) Marshall IJ, Wang Y, Crichton S, McKevitt C, Rudd AG, Wolfe CD: The effects of socioeconomic status on stroke risk and outcomes. Lancet Neurol, 2015; 14: 1206-1218

36) Honjo $K$, Iso $H$, Inoue $M$, Tsugane $S$; Japan Public Health Center-based Prospective Study Group: Education, social roles, and the risk of cardiovascular disease among middle-aged Japanese women: the JPHC Study Cohort I. Stroke, 2008; 39: 2886-2890

37) Krieger N, Chen JT, Selby JV: Comparing individualbased and household-based measures of social class to assess class inequalities in women's health: a methodologi- cal study of 684 US women. J Epidemiol Community Health, 1999; 53: 612-623

38) Martikainen P: Women's employment, marriage, motherhood and mortality: a test of the multiple role and role accumulation hypotheses. Soc Sci Med, 1995; 40: 199212

39) Ikeda N, Saito E, Kondo N, Inoue M, Ikeda S, Satoh T, Wada K, Stickley A, Katanoda K, Mizoue T, Noda M, Iso H, Fujino Y, Sobue T, Tsugane S, Naghavi M, Ezzati M, Shibuya K: What has made the population of Japan healthy? Lancet, 2011; 378: 1094-1105

40) Kadota A, Okamura T, Hozawa A, Kadowaki T, Murakami Y, Hayakawa T, Kita Y, Okayama A, Nakamura Y, Ueshima H; NIPPON DATA80 Research Group: Relationships between family histories of stroke and of hypertension and stroke mortality: NIPPON DATA80, 1980-1999. Hypertens Res, 2008; 31: 15251531

41) Murabito JM, Nam BH, D’Agostino RB Sr, Lloyd-Jones DM, O'Donnell CJ, Wilson PW: Accuracy of offspring reports of parental cardiovascular disease history: the Framingham Offspring Study. Ann Intern Med, 2004; 140: 434-440

42) Watanabe Y, Metoki H, Ohkubo T, Hirose T, Kikuya M, Asayama K, Inoue R, Hara A, Obara T, Hoshi H, Totsune K, Imai Y: Parental longevity and offspring's home blood pressure: the Ohasama study. J Hypertens, 2010; 28: 272277 
Supplemental Table 1. Multivariate-adjusted hazard ratios for stroke incidence among participants aged $60-74$ years and $\geq 75$ years by using the standard Cox regression model

\begin{tabular}{lccc}
\hline Variables & $\begin{array}{c}60-74 \text { years }(n=1502) \\
\text { HR }(95 \% \text { CI })\end{array}$ & $\begin{array}{c}\geq 75 \text { years }(n=563) \\
\text { HR }(95 \% \text { CI })\end{array}$ & $\begin{array}{c}P \text { value for } \\
\text { interaction }\end{array}$ \\
\hline Age (per 1 standard deviation) & $1.64(1.23-2.18)$ & $1.70(1.25-2.31)$ & 0.81 \\
Men & $1.29(0.88-1.91)$ & $1.36(0.89-2.08)$ & 0.57 \\
Hypertension & $2.14(1.54-2.97)$ & $1.58(1.07-2.33)$ & 0.15 \\
Diabetes mellitus & $1.50(1.01-2.22)$ & $0.64(0.32-1.27)$ & 0.023 \\
Heart disease & $1.45(0.91-2.30)$ & $1.02(0.60-1.73)$ & 0.21 \\
Current drinker & $1.39(0.93-2.06)$ & $0.88(0.54-1.42)$ & 0.13 \\
Junior high school & $1.86(1.09-3.18)$ & $1.43(0.66-3.09)$ & 0.59 \\
\hline
\end{tabular}

Hazard ratios (HRs) given with 95\% confidence intervals (CIs) were adjusted for all other variables shown in the table. Age per 1 standard deviation corresponded to 7.6 years. $P$ denotes the significance of interaction between age categories (60-74 years and $\geq 75$ years) and each variable.

Supplemental Table 2. Multivariate-adjusted hazard ratios for stroke incidence according to age category and sex

\begin{tabular}{|c|c|c|c|c|c|c|}
\hline Variables & \multicolumn{3}{|c|}{$60-74$ years $(n=1502)$} & \multicolumn{3}{|c|}{$\geq 75$ years $(n=563)$} \\
\hline Age (per 1 standard deviation) & $1.43(0.96-2.12)$ & $1.56(1.03-2.35)$ & 0.64 & $1.29(0.77-2.17)$ & $1.24(0.84-1.81)$ & 0.83 \\
\hline Hypertension & $2.25(1.37-3.69)$ & $1.97(1.23-3.16)$ & 0.72 & $1.78(0.90-3.50)$ & $1.47(0.91-2.39)$ & 0.63 \\
\hline Diabetes mellitus & $1.52(0.88-2.60)$ & $1.54(0.83-2.83)$ & 0.96 & $0.21(0.03-1.52)$ & $0.89(0.41-1.94)$ & 0.2 \\
\hline Junior high school & $1.04(0.58-1.88)$ & $7.06(1.82-27.48)$ & 0.012 & $1.18(0.42-3.32)$ & $1.61(0.50-5.22)$ & 0.72 \\
\hline
\end{tabular}

Hazard ratios (HRs) given with 95\% confidence intervals (CIs) were adjusted for all other variables shown in the table. Age per 1 standard deviation corresponded to 7.6 years. $P$ denotes the significance of interaction between sex and each variable. 
Supplemental Table 3. Multivariate-adjusted hazard ratios for cerebral infarction among participants aged $60-74$ years and $\geq 75$ years

\begin{tabular}{lccc}
\hline Variables & $\begin{array}{c}\text { 60-74 years }(n=1502) \\
\text { HR }(95 \% \text { CI })\end{array}$ & $\begin{array}{c}\geq 75 \text { years }(n=563) \\
\text { HR }(95 \% \text { CI })\end{array}$ & $\begin{array}{c}P \text { value for } \\
\text { interaction }\end{array}$ \\
\hline Age (per 1 standard deviation) & $1.57(1.11-2.22)$ & $1.32(0.94-1.86)$ & 0.57 \\
Men & $1.47(0.93-2.33)$ & $0.99(0.61-1.62)$ & 0.19 \\
Hypertension & $2.66(1.74-4.05)$ & $1.40(0.91-2.15)$ & 0.021 \\
Diabetes mellitus & $1.72(1.07-2.76)$ & $0.77(0.37-1.60)$ & 0.05 \\
Heart disease & $1.32(0.76-2.30)$ & $0.96(0.52-1.77)$ & 0.29 \\
Current drinker & $1.19(0.75-1.89)$ & $1.08(0.64-1.85)$ & 0.36 \\
Junior high school & $1.68(0.91-3.10)$ & $1.28(0.56-2.96)$ & 0.7 \\
\hline
\end{tabular}

Hazard ratios (HRs) given with 95\% confidence intervals (CIs) were adjusted for all other variables shown in the table. Age per 1 standard deviation corresponded to 7.6 years. $P$ denotes the significance of interaction between age categories (60-74 years and $\geq 75$ years) and each variable.

Supplemental Table 4. Multivariate-adjusted hazard ratios for hemorrhagic stroke among participants aged $60-74$ years and $\geq 75$ years

\begin{tabular}{lccc}
\hline Variables & $\begin{array}{c}60-74 \text { years }(n=1502) \\
\text { HR }(95 \% \text { CI })\end{array}$ & $\begin{array}{c}\geq 75 \text { years }(n=563) \\
\text { HR }(95 \% \text { CI })\end{array}$ & $\begin{array}{c}P \text { value for } \\
\text { interaction }\end{array}$ \\
\hline Age (per 1 standard deviation) & $1.29(0.78-2.14)$ & $0.80(0.37-1.72)$ & 0.37 \\
Men & $0.55(0.26-1.16)$ & $1.82(0.79-4.18)$ & 0.25 \\
Hypertension & $1.30(0.71-2.38)$ & $2.18(0.81-5.87)$ & 0.46 \\
Diabetes mellitus & $1.08(0.49-2.41)$ & $0.33(0.04-2.50)$ & 0.36 \\
Heart disease & $1.13(0.44-2.86)$ & $1.30(0.43-3.90)$ & 0.84 \\
Current drinker & $2.24(1.09-4.61)$ & $0.60(0.20-1.78)$ & 0.3 \\
Junior high school & $2.10(0.77-5.78)$ & $2.27(0.30-17.39)$ & 0.94 \\
\hline
\end{tabular}

Hazard ratios (HRs) given with 95\% confidence intervals (CIs) were adjusted for all other variables shown in the table. Age per 1 standard deviation corresponded with 7.6 years. $P$ denotes the significance of interaction between age categories (60-74 years and $\geq 75$ years) and each variable. 